\title{
SELETIVIDADE DE INSETICIDAS UTILIZADOS NA CULTURA ALGODOEIRA A OVOS E LARVAS DE TERCEIRO INSTAR DE CYCLONEDA SANGUINEA
}

\author{
E.C. Pedroso ${ }^{2}$, G.A. Carvalho ${ }^{1}$, M.I.S. Leite ${ }^{1}$, D.T. Rezende ${ }^{3}$, A.P. de Moura ${ }^{4}$ \\ ${ }^{1}$ Universidade Federal de Lavras, CP 3037, CEP 37200-000, Lavras, MG, Brasil. E-mail: gacarval@den.ufla.br
}

\section{RESUMO}

\begin{abstract}
Objetivou-se avaliar a seletividade fisiológica de inseticidas utilizados em algodoeiro para ovos e larvas de terceiro instar de Cycloneda sanguinea (Linnaeus, 1763) (Coleoptera: Coccinellidae). Os produtos utilizados em g i.a. $\mathrm{L}^{-1}$ de água foram triflumurom 0,048 (Certero 480 SC), espinosade 0,24 (Tracer 480 SC), clorfenapir 1,2 (Pirate 240 SC), clotianidina 0,33 (Focus 500 PM) e imidaclopride 0,33 $+ß$-ciflutrina 0,042 (Connect $100+12,5$ SC). Utilizou-se água destilada como tratamento testemunha. Tanto ovos quanto larvas foram distribuídos em placas de Petri e tratados com os inseticidas por meio de pulverização em torre de Potter. O delineamento experimental utilizado foi o inteiramente ao acaso, com cinco repetições e seis tratamentos constituídos pelos cinco inseticidas e pela testemunha, sendo que cada parcela foi composta por dez ovos ou dez larvas de terceiro instar. Avaliaram-se o período embrionário e a viabilidade de ovos tratados; sobrevivência e duração de larvas de terceiro instar; sobrevivência e duração dos estágios de desenvolvimento larval e pupal, razão sexual e o total de ovos colocados pelas fêmeas provenientes de ovos e larvas de terceiro instar tratados. Os bioensaios foram conduzidos a $25 \pm 2^{\circ}$ C, UR $60 \pm 10 \%$ e fotofase de $12 \mathrm{~h}$. O inseticida triflumurom 0,048 foi seletivo a ovos do predador e levemente nocivo a larvas de terceiro instar. Espinosade 0,24 foi levemente nocivo a ovos e larvas de terceiro instar, e clorfenapir 1,2; clotianidina 0,33 e imidaclopride 0,33+ $\$$-ciflutrina 0,042 foram prejudiciais a ovos e larvas de terceiro instar de $C$. sanguinea.
\end{abstract}

PALAVRAS-CHAVE: Algodoeiro, coccinelídeo, predador, controlebiológico, agrotóxicos, toxicidade.

\section{ABSTRACT}

SELECTIVITYOFINSECTICIDESUSEDINTHECOTTONCROPTOEGGSANDTHIRD-INSTAR LARVAE OF CYCLONEDA SANGUINEA. The objective of this work was to evaluate the effects of synthetic insecticides used in the cotton crop on eggs and third-instar larvae of the ladybeetle Cycloneda sanguinea (Linnaeus, 1763) (Coleoptera: Coccinellidae). The products used in $g$ a.i. L-1 of water were triflumuron 0.048 (Certero 480 SC), spinosad 0.24 (Tracer 480 SC), chlorfenapyr 1.2 (Pirate 240 SC), chlothianidin 0.33 (Focus $500 \mathrm{WP}$ ) and imidacloprid $0.33+$ B-cyfluthrin 0.042 (Connect $100+12.5$ SC). Distilled water was used as a control. Both eggs and larvae were distributed in Petri dishes and treated with the insecticides by spraying in a Potter's tower. A fully randomized experimental design, with five replications and six treatments consisting of five pesticides and one control was used. Each plot consisted of ten eggs or third-instar larvae. The embryonic period and viability of the treated eggs; survival and duration of third-instar larvae; survival and duration of larval and pupal stages of development; sexual ratio, and the total number of eggs laid by the surviving mated females from treated eggs and third-instar larvae were evaluated. The tests were carried out at $25 \pm 2^{\circ} \mathrm{C}, \mathrm{RH} 60 \pm 10 \%$ and $12 \mathrm{~h}$-photophase. Triflumuron 0.048 was innocuous to the predator's eggs and slightly harmful to third-instar larvae. Spinosad 0.24 was slightly harmful to eggs and third-instar larvae, whereas chlofernapyr 1.2, chlothianidin 0.33 and imidacloprid $0.33+$ B-cyfluthrin 0.042 were harmful to eggs and third-instar larvae of C. sanguinea.

KEY WORDS: Cotton crop, coccinellid, predator, biological control, pesticides, toxicity.

\section{INTRODUÇÃO}

Ocusto dos insumos utilizados no cultivo doalgodoeiro no Brasil representa cerca de $55 \%$ do total da produção, $17 \%$ deste total destinado exclusivamente para a aquisição de inseticidas (RıcheTti et al., 2005). A grande demanda por inseticidas se deve ao fato desta cultura atrair e hospedar um complexo signifi-

${ }^{2}$ Universidade Estadual de São Paulo, Jaboticabal, SP, Brasil.

${ }^{3}$ Universidade Estadual Paulista, Botucatu, SP, Brasil.

${ }^{4}$ Embrapa Hortaliças, Brasília, DF, Brasil. 
cativo de pragas, as quais atacam diversas partes da planta (PEREIRA et al., 2006). Simultaneamente a essa diversidade de pragas, a cultura algodoeira também abriga diversos inimigos naturais, dentre os quais se destacam os predadores pertencentes à família Coccinellidae (CARDOSO; LÁZZAR, 2003). Aproximadamente 490 gêneros e 4.200 espécies de coccinelídeos já foram descritas, das quais $90 \%$ são consideradas benéficas, principalmente por sua ação predadora contra pulgões, cochonilhas, moscas-brancas eácaros (IPERTI, 1999).

Considerando a importância que predadores coccinelídeos, dentre outros inimigos naturais, apresentam na regulação populacional de um complexo de artrópodes herbívoros que ocorre na cultura algodoeira (FonsECA et al., 2008), alguns dos quais são relacionados como importantes organismos-praga dessa malvácea, bem como as crescentes exigências dos mercados consumidores quanto à redução no uso de agrotóxicos para o controle de pragas, quanto ao impacto causado ao ambiente e os efeitos nocivos à saúde de trabalhadores rurais, pesquisas visando a compatibilização do uso de inseticidas e a preservação desses inimigos naturais são de suma importância para avanços em programas de manejo integrado de pragas nessa cultura (TORRES; RUBERSON, 2004; BAstos et al., 2006; FonseCA et al., 2008).

Desta forma, objetivou-se com a realização do presente trabalho avaliar os efeitos da aplicação de inseticidas utilizados na cultura do algodoeiro sobre ovos e larvas de terceiro instar do predador C. sanguinea, em condições controladas.

\section{MATERIAL E MÉTODOS}

Criação do predador C. sanguinea. Adultos do predador foram coletados em plantas de sorgo, Sorghum bicolor (Linnaeus) (Poaceae), no Câmpus da UFLA, distribuídos na proporção de um casal por gaiola de PVC com $10 \mathrm{~cm}$ de diâmetro $\times 10 \mathrm{~cm}$ de altura e mantidos em sala climatizada a $25 \pm 2^{\circ} \mathrm{C}$, UR de $60 \pm 10 \%$ e fotofase de $12 \mathrm{~h}$. Os ovos desses adultos foram retirados e colocados em tubos de vidro de 2,5 cm de diâmetro x 8,5 de altura, onde foram mantidos até a eclosão das larvas, as quais em grupos de 40 foram transferidas para gaiolas de PVC com $14 \mathrm{~cm}$ de diâmetro $x 14 \mathrm{~cm}$ de altura, até a obtenção de adultos. A manutenção da criação foi feita ofertando-se pulgões Schizaphis graminum (Rondani, 1852) (Hemiptera: Aphididae) e ovos de Anagasta kuehniella (Zeller, 1879) (Lepidoptera: Pyralidae) ad libitum como alimento.

Bioensaios com C. sanguinea. Os inseticidas e dosagens avaliadas em $\mathrm{g}$ i.a. $\mathrm{L}^{-1}$ de água foram: triflumurom 0,048 (Certero 480 SC), espinosade 0,24 (Tracer 480 SC), clorfenapir 1,2 (Pirate 240 SC), clotianidina 0,33 (Focus 500 PM), imidaclopride 0,33 $+ß$-ciflutrina 0,042 (Connect $100+12,5 S C$ ). Água foi utilizada como tratamento testemunha. A pulverização dos produtos foi realizada por meio de torre de Potter regulada à pressão de $15 \mathrm{lb} \mathrm{pol}^{-2}$, garantindo aplicação de 1,5 $\pm 0,5 \mathrm{mg}$ de calda $\mathrm{cm}^{-2}$, de acordo com metodologia recomendada pela "International Organization for Biological and Integrated Control of Noxious Animals and Plants (IOBC) ".

Cinquenta ovos por tratamento, com até 24 horas de idade, foram retirados da criação em laboratórioe distribuídos em placas de Petri de $10 \mathrm{~cm}$ de diâmetro interno, onde receberam a aplicação dos produtos em torre de Potter. Em seguida, foram transferidos, em grupos de dez, para placas de Petri de $7 \mathrm{~cm}$ de diâmetro externo que foram vedadas com filme plástico de PVC. Determinaram-se o período embrionário mediante a contagem dos dias até a eclosão das larvas, e a viabilidade dos ovos pela percentagem delarvas que eclodiram, com auxílio de microscópio estereoscópico (40x).

As larvas de primeiro instar oriundas dos ovos tratados foram individualizadas em placas de Petri de $5 \mathrm{~cm}$ de diâmetro interno, forradas com papelfiltro para manutenção da umidade e de local para oviposição. As larvas foram alimentadas por meio da oferta de pulgões $S$. graminum e de ovos de $A$. kuehniella, e acompanhadas até a obtenção de adultos. A cada mudança de instar as larvas foram transferidas para novas placas, procedendo-se novamente $o$ umedecimento do papel-filtro com água destilada. Determinaram-se a duração e sobrevivência das fases dedesenvolvimento delarvase pupas, ea razãosexual.

Para avaliar o efeito dos produtos sobre larvas de C. sanguinea, utilizaram-se cinquenta larvas de terceiro instar por tratamento, as quais foram colocadas em placa de Petri de $10 \mathrm{~cm}$ de diâmetro etratadascom osinseticidasem torre dePotter. Logo após a aplicação dos produtos, as larvas foram individualizadas em placas de Petri de $5 \mathrm{~cm}$ de diâmetro, alimentadas conforme descrito anteriormente e mantidas em condições climatizadas até a formação de pupas. Avaliaram-se a sobrevivência e duração das fases de desenvolvimento de larvas e pupas, e a razão sexual dos adultos obtidos.

Para o estudo dos efeitos dos produtos sobre insetos adultos oriundos de ovos e larvas tratadas, formaram-se casais os quais foram alimentados conforme já descrito e mantidos nas mesmas condições mencionadas anteriormente. Os casais foram individualizados em gaiolas de PVC com 14 $\mathrm{cm}$ de diâmetro $\times 14 \mathrm{~cm}$ de altura. Foi registrado o número total de ovos colocados durante dez dias após o período de pré-oviposição.

O delineamento estatístico utilizado foi o inteiramente ao acaso com cinco repetições contendo, respectivamente, dez ovos ou larvas de terceiro instar 
em cada repetição. Para medir os efeitos dos compostos sobre os adultos sobreviventes, utilizaram-se no mínimo cinco casais por tratamento, sendo cada parcela formada por um casal.

Análise dos dados obtidos. Os dados obtidos foram submetidos à análise de variância e as médias dos tratamentos comparadas pelo teste de Tukey, a $5 \%$ de significância, por meio do programa $R$ versão 2.5.1 (R Development Core Team, 2007).

O efeito total (E) de cada produto foi calculado utilizando-se a equação proposta por VEIRE et al. (1996), onde $\mathrm{E}=100 \%$ - (100\% - Ma) x ER, em que: $\mathrm{Ma}=$ mortalidade corrigida em função do tratamento testemunha, calculada pela fórmula de Abbott (ABвотт, 1925) e ER (efeito do produto no número de ovos colocados) $=\mathrm{Rt} \times \mathrm{Rc}$ (onde Rt $=$ número médio de ovos obtidos no tratamento com o produto, e Rc = número médio de ovos obtidos no tratamento testemunha). Após o cálculo do efeito total, os produtos foram enquadrados em classes toxicológicas, conforme a seguir: classe $1=$ inócuo $(\mathrm{E}<30 \%)$, classe 2 = levemente nocivo $(30 \% \leq \mathrm{E} \leq 80 \%)$, classe $3=$ moderadamente nocivo $(80<\mathrm{E} \leq 99)$ e classe $4=$ nocivo ( $\mathrm{E}>99 \%$ ), de acordo com a escala proposta por membros da IOBC (Hassan; Degrande, 1996; Veire et al., 1996; HASSAN, 1997; VeIre et al., 2002).

\section{RESULTADOS E DISCUSSÃO}

Efeito dos inseticidas aplicados sobre ovos de C. sanguinea no desenvolvimento do predador até a fase adulta. Os inseticidas clotianidina e imidaclopride + -ciflutrina aplicados sobre os ovos do predador impediram em $100 \%$ a eclosão das larvas (Tabela 1).

Esses compostos pertencem ao grupo químico dos neonicotinoides e apresentam baixos valores de coeficiente de partição octanol/água $\left(\log \mathrm{K}_{\mathrm{ow}}\right)$, sendo de 0,70 e 0,59, respectivamente (HoffMANN et al., 2009; LoGNOW $\left.^{\odot}, 2010\right)$. A alta toxicidade desses compostos pode estar relacionada à sua menor lipofilicidade, $\mathrm{o}$ que pode aumentar a sua capacidade de penetração no interior dos ovos, afetando diretamente a sobrevivência dos embriões.

Os resultados da aplicação de imidaclopride em ovos de C. sanguinea, observados neste estudo, assemelharam-se aos de Youn et al. (2003) que, ao aplicarem esse mesmo produto (dosagem de 0,05 g i.a. $\mathrm{L}^{-1}$ de água) em ovos de Harmonia axyridis (Pallas, 1773) (Coleoptera, Coccinellidae), também constataram total inviabilidade dos ovos tratados.

Espinosade e clorfenapir também reduziram a viabilidade dos ovos tratados, possibilitando, porém, a eclosão média de $88 \%$ das larvas, diferentemente do triflumurom, que apresentou média de $92 \%$ de viabilidade, estatisticamente semelhante à viabilidade observada na testemunha, que foi de $96 \%$ (Tabela 1 ).

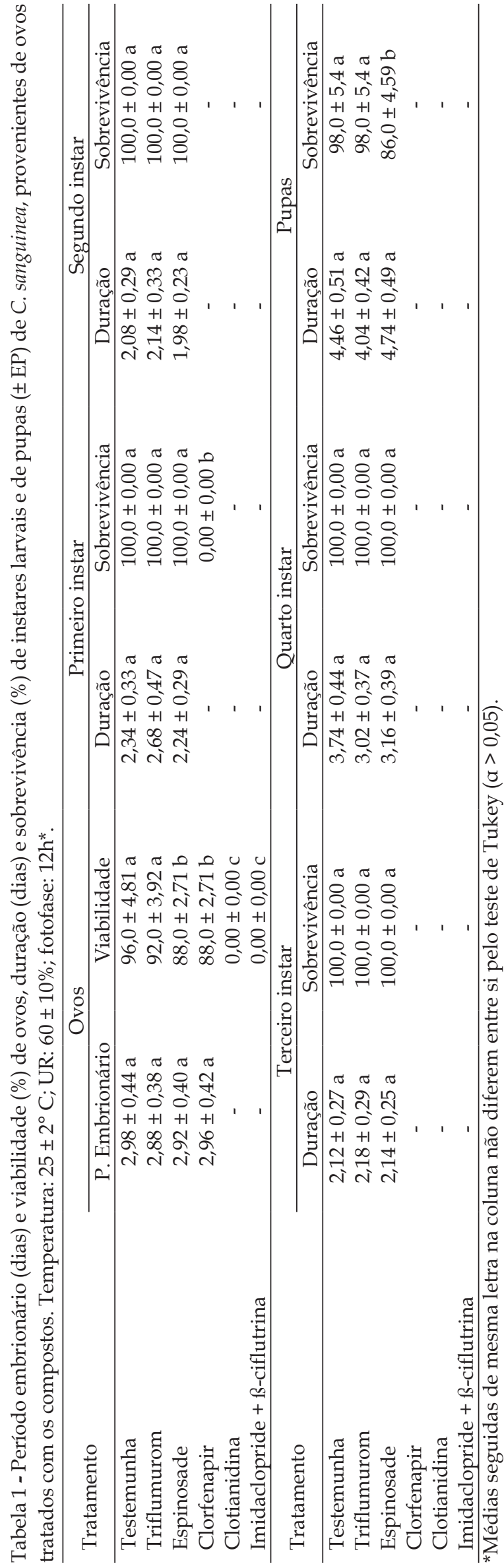


Mesmo tendo possibilitado a eclosão de $88 \%$ das larvas, clorfenapir causou a morte, logo no início do primeiro instar, de $100 \%$ das larvas oriundas de ovos tratados (Tabela 1). Acredita-se que essas larvas tenham se contaminaram com os resíduos do produto presentes na superfície dos ovos tratados, mais especificamente no córion, uma vez que inseticidas com $\log \mathrm{K}_{\mathrm{ow}}$ maiores $(4,83)\left(\right.$ LoGNOW $\left.^{\odot}, 2010\right)$ são mais lipofílicos.

De modo geral, segundo CHAPMAN (1998) e KLOWDEN (2007), o ovo dos insetos é constituído por um núcleo, um citoplasma e uma grande quantidade de "gema", sendo envolto por um invólucro formado pelo envelope vitelínico, por uma camada de ceras e pelo córion, este último constituído pelo endocórion e pelo exocórion. Ainda segundo esses autores, o córion é uma estrutura bastante complexa, sendo que mais de $90 \%$ deste é constituído por proteínas. Acredita-se, portanto, que a constituição do córion, notadamente a presença da camada de ceras, pode influenciar na retenção de certa quantidade de substâncias químicas com propriedades lipofílicas, como no caso do inseticida clorfenapir, conforme mencionado anteriormente, e interferir na mortalidade das larvas recém-eclodidas. O hábito que as larvas de coccinelídeos apresentam de permanecerem no córion dos ovos, após a eclosão, por um período de até 24 horas, pode também favorecer sua contaminação (HODEK, 1973).

A duração dos estádios larvais do predador e sua sobrevivência não foram afetadas por triflumurom e espinosade, tendo-se registrado sobrevivência de $100 \%$ em todos os instares (Tabela 1). Esses produtos não afetaram a duração das pupas, as quais apresentaram médias de 4,04 e 4,74 dias, respectivamente, igualando-se estatisticamenteentre si eao tratamento controle, onde se observou duração de 4,46 dias.

Referente à sobrevivência de pupas do predador oriundas de ovos tratados, espinosadereduziu significativamente essa característica biológica, diferindose de triflumurom e do tratamento controle, onde as pupas de cada um apresentaram médias de $98 \%$ de sobrevivência (Tabela 1). Esses dois compostos não afetaram a razão sexual de $C$. sanguinea, tendo sido observados valores de 0,59 para os espécimes tratados com triflumurom; 0,51 para os tratados com espinosade e 0,61 para aqueles do tratamento controle (Dados não ilustrados).

A não observância de ação letal de triflumurom sobre ovos de C. sanguinea, bem como sobre os demais estágios de desenvolvimento do predador, corrobora com os resultados de CARVALHO et al. (2002a) que, ao tratarem ovos de Chrysoperla externa (Hagen, 1861) (Neuroptera: Chrysopidae) com esse produto, na dosagem de 0,0375 gi.a. $\mathrm{L}^{-1}$, também não verificaram efeito ovicida, nem sobre larvas de primeiro instar oriundas de ovos tratados. Acredita-se que a inocui- dade de triflumurom, tanto a C. sanguinea como a C. externa, quando aplicado sobre ovos dessas duas espécies de predadores, esteja relacionada à baixa persistência apresentada por esse composto, uma vez que, em estudos de persistência desenvolvidos por CARVALHO et al. (2002b), triflumurom (0,15 g i.a. $\left.\mathrm{L}^{-1}\right)$ foi classificado como inseticida de vida curta ( $<5$ dias de persistência), em testes realizados com o parasitoide de ovos Trichogramma pretiosum Riley, 1879 (Hymenoptera: Trichogrammatidae), mesmo quando testado em dosagens três vezes superior à utilizada no presente estudo.

Efeito dos inseticidas aplicados sobre larvas do terceiro instar de $C$. sanguinea, no desenvolvimento do predador até a fase adulta. A duração do terceiro e quarto instares não foi afetada por triflumurom e espinosade, que também não apresentaram diferenças quanto à sobrevivência de larvas (Tabela 2). Resultados semelhantes foram observados por GaLvanetal.(2006) que constataram que ajoaninha $H$. axyridis não foi afetada quando tratada diretamente com espinosade $\left(0,47\right.$ g i.a. $\left.\mathrm{L}^{-1}\right)$ ou quando exposta aos seus resíduos presentes em placas de Petri, o que demonstra a inocuidade do espinosade a essas espécies de coccinelídeos.

Triflumurom e espinosade, quando aplicados sobre larvas de terceiro instar de C. sanguinea, não afetaram a duração da fase de pupa desse predador, todavia, reduziram a sobrevivência das pupas para $79 \%$ e $81 \%$, respectivamente. Espinosade ainda interferiu na razão sexual do inseto, alterando-a para 0,5 , em comparação com triflumurom e com o tratamento controle, que apresentaram razões sexuais de 0,6 e 0,7 , respectivamente, sem diferirem estatisticamente entre si (Tabela 2).

Clotianidina, imidaclopride + $\beta$-ciflutrina e clorfenapir provocaram a mortalidade de $100 \%$ das larvas de terceiro instar tratadas (Tabela 2). Clotianidina e imidaclopride $+\beta$-ciflutrina causaram efeito letal imediatamente após sua aplicação, enquanto que clorfenapir possibilitou que $60 \%$ das larvas sobrevivessem até dois dias após serem tratadas, quando então as larvas sobreviventes morreram sem completar o terceiro instar.

SCARPELLINI et al. (2007) verificaram que acetamipridee tiametoxam, ambos avaliados na dosagem de $0,15 \mathrm{~g}$ i.a. $\mathrm{L}^{-1}$ e pertencentes ao grupo químico dos neonicotinoides, assim como a clotianidina e o imidaclopride, este último presente na mistura com a $\beta$-ciflutrina, e testados no presente estudo, não foram seletivos para inimigos naturais presentes em agroecossistema algodoeiro, incluindo C. sanguinea, o que demonstra a elevada toxicidade de alguns inseticidas pertencentes a esse grupo químico a alguns importantes inimigos naturais de pragas agrícolas. Os efeitos prejudiciais de alguns inseticidas neonicotinoides sobre outros importantes 
artrópodes predadores também foram reportados por vários outros autores (Youn et al., 2003; LUCAS et al., 2004; TORRES; RUBERSON, 2004; CZEPAK et al., 2005; Cloyd; Dickinson, 2006; Kim et al., 2006), que verificaram elevada mortalidade causada por esse grupo de inseticidas a vários inimigos naturais.

Youn et al. (2003) trataram larvas de primeiro e segundo instares de $H$. axyridis com imidaclopride $(0,05$ gi.a. $\left.\mathrm{L}^{-1}\right)$ por meio tópico etodos os espécimes tratados morreram imediatamente após serem contaminados. LucAs et al. (2004) expuseram larvas de terceiro instar de Coleomegilla maculata lengi Timberlake, 1943 (Coleoptera:Coccinellidae) a superfícies tratadas com imidaclopride $\left(0,67\right.$ g i.a. $\left.\mathrm{L}^{-1}\right)$ e verificaram $100 \%$ de mortalidade. SMIтH; CAVE (2006) comprovaram que imidaclopride $\left(0,106\right.$ g i.a. $\left.\mathrm{L}^{-1}\right)$ causou a morte de $100 \%$ das larvas de Rhyzobius lophanthae (Blaisdell, 1892) (Coleoptera: Coccinellidae), quando expostas ao produto sob condições laboratoriais.

Estes resultados comprovam, conformejá comentado anteriormente, a alta toxicidade dos compostos neonicotinoides. De acordo com TomizAWA; CASIDA (2003) e TOMIZAWA; CASIDA (2005), os inseticidas neonicotinoides atuam nos insetos como agonistas nos receptores pós-sinápticos nicotínicos da acetilcolina (nAChR). Nos insetos, esses receptores encontramse ampla e predominantemente distribuídos em algumas regiões do sistema nervoso central, sendo não apenas responsáveis por uma rápida neurotransmissão, mas também sendo considerados importantes alvos para a ação de inseticidas.

Quanto ao efeito total (E) dos produtos fitossanitários sobre ovos e larvas tratados, e sobre a reprodução dos adultos sobreviventes, clorfenapir, clotianidina e imidaclopride $+\beta$-ciflutrina foram enquadrados na classe 4 , sendo considerados nocivos; espinosade foi enquadrado na classe 2 , ou seja, levemente nocivo, e triflumurom foi inserido na classe 1 (inócuo) no ensaio com ovos e, na classe 2 (levemente nocivo) no ensaio com larvas do predador (Tabela 3).

As classes de toxicidade obtidas para a clotianidina, e para o imidaclopride em mistura com a $\beta$-ciflutrina no presente trabalho, confirmam os resultados obtidos por CARVALHO et al. (2002c) e por VeIre et al. (2002), para ninfas de quarto instar de Orius insidiosus (Say, 1832) e de primeiro instar de Oriuslaevigatus(Fieber,1860)(Hemiptera:Anthocoridae), respectivamente. Esses autores consideraram o imidaclopride prejudicial a essas duas espécies, com efeito total (E) de $100 \%$ (classe 4). Conforme mencionado anteriormente, esses resultados demonstram quealguns inseticidas neonicotinoides sãoaltamente prejudiciais a várias espécies de inimigos naturais de pragas, o que pode influenciar negativamente tanto na conservação como na manutenção desses organismos benéficos nos agroecossistemas.

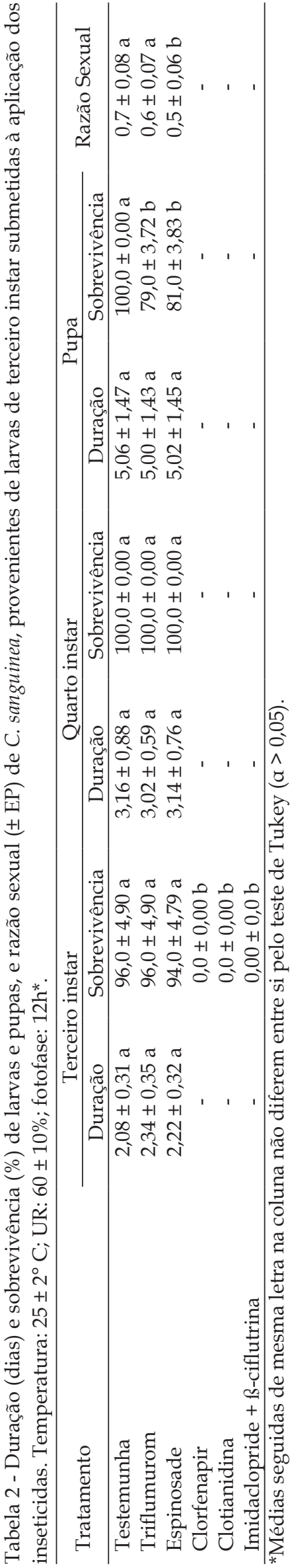


Tabela 3 - Mortalidade (Ma) (\%), número de ovos, efeito total (E) (\%) e classificação dos inseticidas em função da escala de toxicidade proposta pela IOBC (Classe), de espécimes oriundos de ovos e de larvas de terceiro instar de Cycloneda sanguinea tratados com os compostos. Temperatura: $25 \pm 2{ }^{\circ} \mathrm{C}$; UR: $60 \pm 10 \%$; fotofase: $12 \mathrm{~h}$.

\begin{tabular}{|c|c|c|c|c|}
\hline \multirow{2}{*}{ Tratamento } & $\mathrm{Ma}^{1}$ & No de ovos $^{2}$ & $E^{3}$ & Classe $^{4}$ \\
\hline & \multicolumn{4}{|c|}{ Ovos } \\
\hline Testemunha & - & 174,10 & - & - \\
\hline Triflumurom & 4,17 & 125,70 & 29,00 & 1 \\
\hline Espinosade & 8,33 & 124,10 & 35,00 & 2 \\
\hline Clorfenapir & 8,33 & - & 100,00 & 4 \\
\hline Clotianidina & 100,00 & - & 100,00 & 4 \\
\hline Imidaclopride $+ß$-ciflutrina & 100,00 & - & 100,00 & 4 \\
\hline \multirow{2}{*}{ Tratamento } & $\mathrm{Ma}^{1}$ & $\mathrm{~N}^{\mathrm{o}}$ de ovos ${ }^{2}$ & $\mathrm{E}^{3}$ & Classe $^{4}$ \\
\hline & \multicolumn{4}{|c|}{ Larvas de terceiro instar } \\
\hline Testemunha & - & 165,20 & - & - \\
\hline Triflumurom & 0,00 & 88,10 & 47,00 & 2 \\
\hline Espinosade & 2,08 & 91,60 & 46,00 & 2 \\
\hline Clorfenapir & 100,00 & - & 100,00 & 4 \\
\hline Clotianidina & 100,00 & - & 100,00 & 4 \\
\hline Imidaclopride $+ß$-ciflutrina & 100,00 & - & 100,00 & 4 \\
\hline
\end{tabular}

${ }_{1}^{1}(\mathrm{Ma})$ - Mortalidade de ovos e de larvas tratados corrigida pela fórmula de Abbott (Аввотт, 1925);

${ }^{2}$ Número total de ovos, nos dez dias após o período de pré-oviposição, colocados pelas fêmeas sobreviventes oriundas de ovos e larvas de terceiro instar tratadas com os inseticidas;

${ }^{3}$ Efeito total do produto sobre o predador após tratamento de ovos ou larvas;

${ }^{4}$ Classe de toxicidade atribuída ao composto, segundo escala da IOBC (HASSAN; Degrande, 1996; VeIRE et al., 1996; HASSAN, 1997; VEIRE et al., 2002).

Não foi possível se realizar comparações entre as classes de toxicidade atribuídas aos inseticidas avaliados no presente trabalho, para a mesma espécie de predador estudada, e para a maior parte dos inseticidas testados, uma vez que não foram encontrados na literatura estudos que tenham utilizado a mesma metodologia, ou seja, a metodologia preconizada pela IOBC.

Entretanto, com base nos resultados aqui apresentados e discutidos, acredita-se que os inseticidas espinosade e triflumurom mostram-se adequados para serem utilizados juntamente com o predador C. sanguinea, no controle de pragas na cultura do algodoeiro.

\section{CONCLUSÕES}

Triflumurom é seletivo a ovos do predador e levemente nocivo a larvas de terceiro instar.

Espinosade é levemente nocivo a ovos e larvas de terceiro instar de $C$. sanguinea.

Clorfenapir, clotianidina, e imidaclopride + B-ciflutrina são tóxicos a ovos e larvas de terceiro instar de C. sanguinea.

Em função da baixa toxicidade, os inseticidas triflumurom e espinosade podem ser recomendados em programas de manejo de pragas na cultura algodoeira visando a preservação dessa espécie de predador nas fases de ovo e larva.

\section{AGRADECIMENTOS}

À Coordenação de Aperfeiçoamento dePessoal de Nível Superior (CAPES), pela concessão da bolsa de estudos ao primeiro autor e à Fundação de Amparo à Pesquisa do Estado de Minas Gerais, pelo suporte financeiro necessário à realização desse trabalho.

\section{REFERÊNCIAS}

ABBOTT, W.S. A method of computing the effectiveness of an insecticide. Journal of Economic Entomology, v.15, n.2, p.265-267, 1925.

BASTOS, C.S.; ALMEIDA, R.P.; SUINAGA, F.A. Selectivity of pesticides used on cotton (Gossypium hirsutum) to Trichogramma pretiosum reared on two laboratory-reared hosts. Pest Management Science, v.62, n.1, p.91-98, 2006.

CARDOSO, J.T.; LÁZZAR, S.M.N. Comparative biology of Cycloneda sanguinea (Linnaeus, 1763) and Hippodamia convergens Guérin-Méneville, 1842 (Coleoptera, Coccinellidae) focusing on the control of Cinara spp. (Hemiptera, Aphididae). Revista Brasileira de Entomologia, v.47, n.3, p.443-446, 2003.

CARVALHO, G.A.; CARVALHO, C.F.; SOUZA, B.; ULHÔA, J.L.R. Seletividade de inseticidas a Chrysoperla externa (Hagen) (Neuroptera: Chrysopidae). Neotropical Entomology, v.31, n.4, p.615-621, 2002a. 
CARVALHO, G.A.; REIS, P.R.; MORAES, J.C.; FUINI, L.C.; ROCHA, L.C.D.; GOUSSAIN, M.M. Efeitos de alguns inseticidas utilizados na cultura do tomateiro (Lycopersicon esculentum Mill.) a Trichogramma pretiosum Riley, 1879 (Hymenoptera: Trichogrammatidae). Ciência e Agrotecnologia, v.26, n.6, p.1160-1166, 2002b.

CARVALHO, G.A.; DRUMMOND, F.A.; ULHÔA, J.L.R.; ROCHA, L.C.D. Efeito de inseticidas sobre Orius insidiosus (Say, 1832) (Hemiptera: Anthocoridae). Ciência e Agrotecnologia, v.26, n.1, p.52-56, 2002c.

CHAPMAN, R.F. The Insects: Structure and function. Cambridge: Cambridge University Press, 1998. 770p.

CLOYD, R.A.; DICKINSON, A. Effect of insecticides on mealybug destroyer (Coleoptera: Coccinellidae) and parasitoid Leptomastix dactylopii (Hymenoptera: Encyrtidae), natural enemies of citrus mealybug (Homoptera: Pseudococcidae). Journal of Economic Entomology, v.99, n.5, p.1596-1604, 2006.

CZEPAK, C.; FERNANDES, P.M.; ALBERNAZ, K.C.; RODRIGUES, O.D.; SILVA, L.M.; SILVA, E.A.; TAKATSUKA, F.S.; BORGES, J.D. Seletividade de inseticidas ao complexo de inimigos naturais na cultura do algodão (Gossypium hirsutum L.). Pesquisa Agropecuária Tropical, v.35, n.2, p.123-127, 2005.

FONSECA, P.R.B.; BERTONCELLO, T.F.; RIBEIRO, J.F.; FERNANDES, M.G.; DEGRANDE, P.R. Seletividade de inseticidas aos inimigos naturais ocorrentes sobre o solo cultivado com algodoeiro. Pesquisa Agropecuária Tropical, v.38, n.4, p.304-309, 2008.

GALVAN, T.L.; KOCH, R.L.; HUTCHISON, W.D. Toxicity of indoxacarb and spinosad to the multicolored Asian lady beetle, Harmonia axyridis (Coleoptera, Coccinellidae), via three routes of exposure. Pest Management Science, v.62, n.9, p.797-804, 2006.

HASSAN, S.A. Métodos padronizados para testes de seletividade, com ênfase em Trichogramma. In: PARRA. J.R.P.; ZUCCHI, R.A. (Ed.). Trichogramma e o controle biológico aplicado. Piracicaba: FEALQ, 1997. p.207-233.

HASSAN, S.A.; DEGRANDE, P.E. Methods to test the side-effects of pesticides on Trichogramma. In: PARRA, J.R.P.; ZUCCHI, R.A. (Ed.). Curso de controle biológico com Trichogramma. Piracicaba: FEALQ, 1996. p.63-74.

HODEK, I. Biology of Coccinellidae. Prague: Academic of Sciences, 1973. 260p.

HOFFMANN, E.J.; VANDERVOORT, C.; WISE, J.C. Curative activity of insecticides against plum curculio (Coleoptera: Curculionidae) in tart cherries. Journal of Economic Entomology, v.102, n.5, p.1864-1873, 2009.

IPERTI, G. Biodiversity of predaceous Coccinellidae in relation to bioindication and economic importance. Agriculture, Ecosystems and Environment, v.74, n.1/3, p.323-342, 1999.
KIM, D.-S.; BROOKS, D.J.; RIEDL, H. Lethal and sublethal effects of abamectin, spinosad, methoxyfenozide and acetamiprid on the predaceous plant bug Deraeocoris brevis in the laboratory. BioControl, v.51, n.4, p.465-484, 2006.

KLOWDEN, M.J. Physiological systems in insects. New York: Academic Press, 2007. 688p.

LOGNOW. A databank of evaluated octanol-water partition coefficients $(\log P)$. Disponível em: <http://logkow.cisti. nrc.ca/logkow/search.html>. Acesso em: 8 abr. 2010.

LUCAS, É.; GIROUX, S.; DEMOUGEOT, S.; DUCHESNE, R.-M.; CODERRE, D. Compatibility of a natural enemy, Coleomegilla maculata lengi (Col., Coccinellidae) and four insecticides used against the Colorado potato beetle (Col., Chrysomelidae). Journal of Applied Entomology, v.128, n.3, p.233-239, 2004.

PEREIRA, M.J.B.; ALBUQUERQUE, F.A.; BASTOS, C.S. Pragas do algodoeiro: identificação, biologia e sintomas de ataque. Revista Brasileira de Oleaginosas e Fibrosas, v.10, n.3, p.1073-1117, 2006.

R DEVELOPMENT CORE TEAM: R: a language and environment for statistical computing. Vienna: R Foundation for Statistical Computing, 2007.

RICHETTI, A.; LAMAS, F.M.; STAUT, L.A.; FABRICIO, A.C. Estimativa do custo de produção de algodão, Safra 2005/06, para Mato Grosso do Sul e Mato Grosso. Dourados: Embrapa, 2005. (Embrapa. Comunicado Técnico).

SCARPELLINI, J.R.; FARIA, A.M.; RODRIGUES, F.E. Seletividade fisiológica de aficidas sobre o complexo de inimigos naturais de pragas do algodoeiro utilizando-se diferentes métodos de amostragem. 2007. Disponível em: <http://www.cnpa.embrapa.br/produtos/algodao/ publicacoes/trabalhos_cba4/103.pd>. Acesso em: 18 jan. 2008.

SMITH, T.R.; CAVE, R.D. Pesticide susceptibility of Cybocephalus nipponicus and Rhyzobius lophanthae (Coleoptera, Cybocephalidae, Coccinellidae). Florida Entomologist, v.89, n.4, p.502-507, 2006.

TOMIZAWA, M.; CASIDA, J.E. Selective toxicity of neonicotinoids attributable to specificity of insect and mammalian nicotinoid receptors. Annual Review of Entomology, v.48, p.339-364, 2003.

TOMIZAWA, M.; CASIDA, J.E. Neonicotinoid insecticide toxicology: mechanisms of selective action. Annual Review of Pharmacology and Toxicology, v.45, p.247-268, 2005.

TORRES, J.B.; RUBERSON, J.R. Toxicity of thiamethoxam and imidacloprid to Podisus nigrispinus (Dallas) (Heteroptera: Pentatomidae) nymphs associated to aphid and whitefly control in cotton. Neotropical Entomology, v.33, n.1, p.99-106, 2004. 
VEIRE, M.; SMAGGHE, G.; DEGHEELE, D.Laboratory test method to evaluate the effect of 31 pesticides on the predatory bug, Orius laevigatus (Het: Anthocoridae). Entomaphaga, v.41, n.2, p.235-243, 1996.

VEIRE, M.; STERK, G.; STAAIJ, M.; RAMAKERS, P.M.J.; TIRRY, L. Sequential testing scheme for the assessment of the side-effects of plant protection products on the predatory bug Orius laevigatus. Bio Control, v.47, n.1, p.101-113, 2002.
YOUN, Y.N.; SEO, M.J.; SHIN, J.G.; JANG, C.; YU, Y.M. Toxicity of greenhouse pesticides to multicolored Asian lady beetles, Harmonia axyridis (Coleoptera: Coccinellidae). Biological Control, v.28, n.2, p.164-170, 2003.

Recebido em 12/7/10

Aceito em 22/11/11 